$$
\text { Pontifícia } \text { Universidade }_{\text {do Rio de Janeiro }}
$$

Danilo Caiano Delgado

\title{
Moment-based estimation of nonlinear models
}

Thesis presented to the Postgraduate Program in Economics of the Departamento de Economia,PUCRio as partial fulfillment for the degree of Mestre em Economia.

Advisor: Prof. Marcelo Cunha Medeiros

Rio de Janeiro, September 2012 


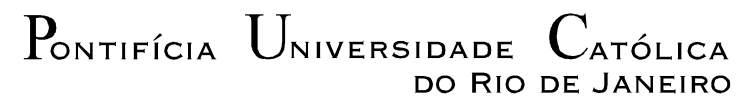
DO RIO DE JANEIRO

Danilo Caiano Delgado

\section{Moment-based estimation of nonlinear models}

Thesis presented to the Postgraduate Program in Economics of the Departamento de Economia, PUC-Rio as partial fulfilment of the requirements for the degree of Mestre em Economia. Approved by the following commission.

Prof. Marcelo Cunha Medeiros

Advisor

Departamento de Economia - PUC-Rio

Prof. Álvaro Veiga

Departamento de Engenharia Elétrica - PUC-Rio

Prof. Cristiano Fernandes

Departamento de Engenharia Elétrica - PUC-Rio

Prof. Monica Herz

Coordinator of the Centro de

Ciências Sociais - PUC-Rio

Rio de Janeiro, September 28th 2012 
All rights reserved

\section{Danilo Caiano Delgado}

Undergraduate degree in Economics from Universidade Federal do Rio de Janeiro in 2009 and Master's degree in Economics from PUC-Rio in 2012.

Bibliographic data

Delgado, Danilo Caiano

Moment-based estimation of nonlinear models/ Danilo Caiano Delgado; advisor:Marcelo Medeiros;- 2012.

$41 \mathrm{f}$ : il. ; $30 \mathrm{~cm}$

Dissertação (Mestrado em Economia)-Pontifícia Universidade Católica do Rio de Janeiro, Rio de Janeiro, 2012.

Incluí referências bibliográficas.

1. Economia - Teses. 2. Modelos não-lineares 3. Estimador com função controle 4. Estimador não-linear de máxima verossimilhança de informação limitada I. Medeiros, Marcelo. II. Pontifícia Universidade Católica do Rio de Janeiro. Departamento de Economia. III. Título.

CDD:330 


\section{Resumo}

Delgado, Danilo Caiano; Medeiros, Marcelo Cunha. Estimação de modelos não-lineares baseados em condições de momento. Rio de Janeiro, 2013. 41 p. Dissertação de Mestrado - Departamento de Economia, Pontifícia Universidade Católica do Rio de Janeiro.

O objetivo desta dissertação é comparar através de um estudo de simulação diferentes estimadores de modelos não-lineares. Nós consideramos neste trabalho o estimador não-linear de mínimos quadrados em dois estágios (NL2SLS), o estimador não-linear de máxima verossimilhança de informação limitada (LIML) e o estimador com função controle $(\mathrm{CF})$. Os resultados mostram que os estimadores CF e LIML possuem em geral uma performance superior ao do NL2SLS para os modelos selecionados. O trabalho considera uma aplicação de uma Curva de Phillips não-linear para a Economia Brasileira.

\section{Palavras-chave}

modelos não-lineares; estimador com função controle; estimador não-linear de máxima verossimilhança de informação limitada (LIML); estimador não-linear de mínimos quadrados em dois estágios (NL2SLS) 


\section{Abstract}

Delgado, Danilo Caiano; Medeiros, Marcelo Cunha (Advisor). Momentbased estimation of nonlinear models. Rio de Janeiro, 2013. 41 p. Dissertação de Mestrado - Departamento de Economia, Pontifícia Universidade Católica do Rio de Janeiro.

The aim of this dissertation is to compare, in a simulation study, different nonlinear estimators for selected models. We consider the two-stage nonlinear least-squares (NL2SLS), the nonlinear limited information maximum likelihood (LIML), and the control function (CF) estimator. Our results show that usually either CF or LIML estimators perform better than the NL2SLS estimator for the selected models. In an application with real data, we consider the estimation a nonlinear Phillips Curve for Brazilian economy.

\section{Keywords}

nonlinear models; control function estimator; nonlinear limited information maximum likelihood estimator (LIML); nonlinear two-stage least squares estimator (NL2SLS) 


\section{Sumário}

1 Introduction 9

2 GMM and nonlinear models estimation 11

3 The Control Function Estimation 14

4 Simulation 16

5 Application 23

6 Conclusion $\quad 25$

$\begin{array}{ll}7 \text { References } & 26\end{array}$

$\begin{array}{lr}\text { Appendix } & 27\end{array}$ 


\section{List of figures}

$\begin{array}{lr}\text { Figure } 1 & 27\end{array}$

$\begin{array}{ll}\text { Figure } 2 & 28\end{array}$

$\begin{array}{lr}\text { Figure } 3 & 29\end{array}$

$\begin{array}{ll}\text { Figure } 4 & 30\end{array}$

$\begin{array}{ll}\text { Figure } 5 & 31\end{array}$

Figure $6 \quad 32$

Figure $7 \quad 33$

$\begin{array}{ll}\text { Figure } 8 & 34\end{array}$

$\begin{array}{ll}\text { Figure } 9 & 35\end{array}$

$\begin{array}{ll}\text { Figure } 10 & 36\end{array}$

$\begin{array}{ll}\text { Figure } 11 & 37\end{array}$

$\begin{array}{ll}\text { Figure } 12 & 38\end{array}$

$\begin{array}{ll}\text { Figure } 13 & 39\end{array}$

Figure 14

Figure 15 


\section{List of tables}

$\begin{array}{lr}\text { Table } 1 & 17\end{array}$

$\begin{array}{lr}\text { Table } 2 & 19\end{array}$

$\begin{array}{ll}\text { Table } 3 & 21\end{array}$

$\begin{array}{ll}\text { Table } 4 & 24\end{array}$ 


\section{Introduction}

Economists often use nonlinear models because they can improve results obtained with linear models. A common method used on the estimation of nonlinear models is the nonlinear two-stage least squares (NL2SLS). In this method, among the several conditions imposed to ensure the parameter estimation, the rank condition is a key one. It states that instrumental variables must be correlated with the gradient vector of the nonlinear function evaluated at the true value of the parameters. In the linear framework, this means that instruments must be correlated with endogenous variables. However, in the nonlinear setting the instruments may have low correlation with gradient vector for some function classes. Then, the rank condition for the nonlinear framework will not be accomplished.

In order to improve correlation between instruments and the gradient vector, Takeshi (1974) derived the optimal instrument for nonlinear instrumental variables estimator. Takeshi (1975) proofed that the nonlinear limited information maximum likelihood (LIML) estimator is asymptotically more efficient than NL2SLS estimator when the endogenous variable is a linear functions of the exogenous variables. Takeshi (1974), Chamberlain (1987), Newey (1990) approximated the optimal instrument through nonparametric regression utilizing constructed instruments such as polynomials.

In this paper we compare the performance between the NL2SLS estimator, the nonlinear limited information maximum likelihood (LIML) estimator and the control function (CF) estimator for specific families of nonlinear functions. Simulated data have been generated to measure the performance of the mentioned estimators. The first example has generated data from an exponential function that is usually found Count Data models. The second example has generated data for the logistic function that is usually found in Smooth Transition Regression Models. The third example uses the same model as in the previous example except that the endogenous variable now is a nonlinear function of the exogenous variable. In the presented examples we compare bias, standard deviation, 
skewness and curtosis of the estimators. Simulation results show that $\mathrm{CF}$ estimator has better results in most of the settings for all settings, followed by the LIML estimator. The results of the developed estimators have presented for simulated data that theirs performance do not differ too much from the NL2SLS estimator. In application with real data, all the estimators have provided results that are close to the underlined economic theory.

Section 2 presents the Generalized Method of Moments (GMM) and estimation methods for nonlinear models and section 3 presents the Control Function Estimator. Section 4 shows results for simulated data and section 5 shows results for an application for a nonlinear Phillips Curve with Brazilian data. Appendix presents histograms for simulated data of Section 4. 


\section{GMM and nonlinear models estimation}

This section presents the Generalized Method of Moments (GMM) used to obtain consistent estimators for nonlinear models. As in Takeshi (1974), consider a data generating process in which

(i) $\{u\}_{t=1}^{T}, T>0$, is a sequence of random variables such that $E\left(u_{z}\right)=0 \mathrm{Vt}$, $E\left(u_{t}^{2}\right)=\sigma_{0}^{2}<\infty \forall t, E\left(u_{t} u_{s}\right)=0 \forall t \neq s ;$

(ii) $g\left(\boldsymbol{x}_{t}, \psi_{0}\right)$ is a nonlinear function of covariates $\boldsymbol{x}_{t} \in \mathbb{R}^{a_{w}}$ indexed by the true parameter $\psi_{0} \in \Psi \subset \mathbb{R}^{k} ;$

(iii) $\{y\}_{t=1}^{T}, T>0$, is generated by the nonlinear model $y_{t}=g\left(\boldsymbol{x}_{t} ; \psi_{0}\right)+u_{t}$;

(iv) $\boldsymbol{x}_{\boldsymbol{t}}$ is an endogenous variable such that $E\left(u_{t} \mid \boldsymbol{x}_{\boldsymbol{t}}\right) \neq 0$.

Define $\dot{g}\left(\boldsymbol{x}_{\boldsymbol{t}} ; \psi_{0}\right)=\left.\frac{a g\left(\boldsymbol{x}_{t} ; \psi\right)}{\partial \psi}\right|_{\psi=\psi_{0}}$. According to this model, we have that $E\left(y_{t} \mid \boldsymbol{x}_{t}\right) \neq g\left(\boldsymbol{x}_{\boldsymbol{t}} ; \psi_{0}\right)$ and, consequently, $E\left(x_{t} \dot{g}\left(\boldsymbol{x}_{\boldsymbol{t}} ; \psi_{0}\right)\right) \neq 0$. In this case, due to endogeneity of $\boldsymbol{x}_{\boldsymbol{t}}$, the standard nonlinear least squares estimator for $\psi_{0}$ is inconsistent.

The endogeneity problem can be dealt with by using the Generalized Method of Moments (GMM). Let $w_{t} \in \mathbb{R}^{q_{w}}$ be a vector of instrumental variables and $z_{t}=z_{i}\left(w_{t}\right) \in \mathbb{R}^{q_{z}} q_{\underline{z}} \geq K . \quad z_{z}\left(w_{t}\right): \mathbb{R}^{q_{w}} \rightarrow \mathbb{R}^{q_{x}}$ is a function of $w_{t}$ such that $q_{g}$ moment conditions are given by $E\left(u_{t} z_{t}\right)=\mathbf{0}$.

Define

$Y_{t}=\left(y_{t}, x_{t}^{\prime}, z_{t}^{\prime}\right), h\left(Y_{t}, \psi\right)=\frac{1}{T} \sum_{t=1}^{T} z_{t}\left[y_{t}-g\left(\boldsymbol{x}_{\dot{t}} ; \psi\right)\right]=\frac{1}{T} \sum_{t=1}^{T} z_{t}\left[u_{t}\right] \quad$ and $\Omega=E\left(u_{t}^{2} z_{t} z_{t}^{\prime}\right)=\sigma_{0}^{2} E\left(z_{\bar{t}} z_{t}^{\prime}\right)$. Let $\bar{\Omega}$ be a consistent estimator for $\Omega$. Then, the GMM estimator is given by

$$
\tilde{\psi}_{G M M}=\operatorname{argmin}_{\psi \in \Psi}\left[h\left(Y_{t} ; \psi\right) \hat{\Omega}^{-1} h\left(Y_{t} ; \psi\right)\right] .
$$


Now

define $\boldsymbol{y}=\left(y_{1}, \ldots, y_{T}\right)^{r}, \boldsymbol{X}=\left(\boldsymbol{x}_{1}, \ldots, \boldsymbol{x}_{T}\right)^{\prime}, g(\boldsymbol{X}, \psi)=\left[g\left(\boldsymbol{x}_{1} ; \psi\right), \ldots, g\left(\boldsymbol{x}_{T} ; \psi\right)\right]^{r}, \quad$ and $Z=\left(\boldsymbol{z}_{1, \ldots, z_{T}}\right)^{\prime}$. As in Takeshi (1974), by taking $\sigma_{0}^{2}$ as constant and $\frac{1}{T} \sum_{t=1}^{T} z_{t} z_{t}^{\prime}$ as a consistent estimator for $E\left(\boldsymbol{z}_{t} \boldsymbol{z}_{t}^{t}\right)$, the nonlinear instrumental variables estimator is

$$
\begin{gathered}
\tilde{\psi}_{G M M}=\operatorname{argmin}_{\psi \in \Psi}\left\{\frac{1}{T} \sum_{t=1}^{T} z_{t}\left[y_{t}-g\left(x_{t} ; \psi\right)\right]^{\prime},\left\{\frac{1}{T} \sum_{t=1}^{T} z_{t} z_{t}^{\prime}\right\}^{-1}\left\{\frac { 1 } { T } \sum _ { t = 1 } ^ { T } z _ { t } \left[y_{t}\right.\right.\right. \\
\left.\left.-g\left(\boldsymbol{x}_{t} ; \psi\right)\right]^{\prime}\right\} \\
=\operatorname{argmin}_{\psi \in \Psi} \frac{1}{T}\left[y-g\left(\boldsymbol{X}_{i} \psi\right)\right]^{\prime} \boldsymbol{Z}\left[\boldsymbol{Z}^{\prime} \boldsymbol{Z}\right\}^{-1} \boldsymbol{Z}^{\prime}\left[y-g\left(\boldsymbol{X}_{i} \psi\right)\right]
\end{gathered}
$$

When $g\left(x_{t} ; \psi\right)$ is nonlinear in both parameters and variables and the instruments are assumed to be fixed in repeated samples, Takeshi (1974) proofs consistency and asymptotic normality of the GMM estimator for IID data. The GMM estimator is also efficient when $g\left(x_{t} ; \psi\right)$ is nonlinear only in the parameters.

An important condition to ensure the identification of $\psi$ is to comply with the first order condition of the optimization problem, which states that $\operatorname{plim}_{t \rightarrow \infty} \boldsymbol{Z}^{\prime} \boldsymbol{g}\left(\boldsymbol{X} ; \psi_{0}\right)$ has full rank. Therefore, the instrumental variables must be correlated with the gradient vector of the nonlinear function. Thus, an instrument that is highly correlated with the endogenous variables in the linear setting may be a weak instrument in a nonlinear framework. Takeshi (1975) shows that the optimal instrument is given by $\boldsymbol{E}\left(\dot{g}\left(\boldsymbol{x}_{\boldsymbol{t}} ; \psi_{0}\right) \mid \boldsymbol{w}_{\vec{t}}\right)$.

Now consider the following linear framework $x_{t}=\Theta_{0} w_{t}+v_{t}, E\left(v_{t} \mid w_{t}\right)=0$, where $\left\{v_{t}\right\}_{t=1}^{T}$ is a sequence of I.I.D. random variables with zero mean and correlated with $u_{t}$. Define $\boldsymbol{W}=\left(\boldsymbol{w}_{1, \ldots,}, \boldsymbol{w}_{T}\right)^{\prime}$, $\widehat{\boldsymbol{V}}=\boldsymbol{X}-\boldsymbol{W}\left(\boldsymbol{W}^{\prime} \boldsymbol{W}\right)^{-1} \boldsymbol{W}^{\prime} \boldsymbol{X}$ and $\boldsymbol{I}$ as the identity matrix of order T. [Takeshi1975] shows that 


$$
\psi_{M V V}=\operatorname{argmin}_{\psi \varepsilon \Psi} \frac{1}{T}\left[y-g\left(X_{;} \psi\right)\right]^{\prime} Z\left\{Z^{\prime}\right\}^{-1} Z^{\prime}[y-g(X ; \psi)]
$$

is more efficient than the GMM estimator.

The GMM optimization problem requires that the instrumental variables must be correlated with the gradient vector in order to ensure that $\operatorname{plim}_{t \rightarrow \infty} \boldsymbol{Z}^{\prime} \boldsymbol{g}\left(\boldsymbol{X}_{;} \boldsymbol{\psi}_{0}\right)$ has full rank. Nevertheless, the optimal instrument depends on the true value of the parameter $\psi_{0}$, that is unknown. The usual procedure is to estimate the parameter through nonlinear two-stage least squares. The first stage obtains a consistent estimator $\hat{\psi}$ for $\psi$ and the second stage uses $E\left(\hat{g}\left(x_{t} ; \tilde{\psi}\right) \mid w_{t}\right)$ as instrument. However, in the case we have weak instruments, the rank condition may not be satisfied and the resulted estimator might be inconsistent. The next section presents the Control Function estimator and how it is used to obtain consistent estimation without rely on the rank condition. 


\section{The Control Function Estimation}

A different approach to estimate nonlinear models is given by the use of the Control Function (CF) estimator. As in Imbens and Wooldridge (2007), consider the linear model

$$
y_{1}=z_{1} \delta_{1}+\alpha_{1} y_{2}+u_{1}
$$

Where $z_{1}$ is a $1 x L_{1}$ strict sub vector of $z$, a $1 x L$ vector of exogenous variables that includes a constant. The $\boldsymbol{L}$ zero covariance conditions are given by

$$
E\left(\mathbf{z}^{\prime} u_{1}\right)=\mathbf{0}
$$

We write the reduced form with an error term as

$$
\begin{gathered}
y_{2}=\boldsymbol{z} \pi_{2}+v_{2}, \\
E\left(z^{\prime} v_{2}\right)=0 .
\end{gathered}
$$

$y_{2}$ is endogenous if $u_{1}$ is correlated with $v_{2}$. Write the linear projection of $u_{1}$ on $v_{2}$, in error form, as

$$
u_{1}=p_{1} v_{2}+e_{1}
$$

where $\rho_{1}=E\left(v_{2} u_{1}\right) / E\left(v_{2}^{2}\right)$. Then, $E\left(v_{2} e_{1}\right)=0$, and $E\left(z^{\prime} e_{1}\right)=\mathbf{0}$ due to uncorrelation of $\mathrm{z}$ with both $u_{1}$ and $v_{2}$. Then, we have

$$
y_{1}=z_{1} \delta_{1}+\alpha_{1} y_{2}+u_{1}=z_{1} \delta_{1}+\alpha_{1} y_{2}+\rho_{1} v_{2}+e_{1} \text {. }
$$

OLS regression of $y_{1}$ on $z_{1}, y_{2}$ and $v_{2}$ estimates consistently $\alpha_{1}$ and $\delta_{1}$ because $e_{1}$ is uncorrelated with $z_{1}, y_{1}$ and $v_{2}$ by construction. However, $v_{2}$ is not observed. The suggested approach is to estimate $\pi_{2}$ in a first moment by running OLS regression on the reduced form equation. This first stage will provide $\hat{\nu}_{2}=y_{2}-z \hat{\pi}_{2}$, that will replace $v_{2}$ in the structural equation:

$$
y_{1}=z_{1} \delta_{1}+\alpha_{1} y_{2}+\rho_{1} \hat{\partial}_{2}+e_{1}+\rho_{1} z\left(\hat{\pi}_{2}-\pi_{2}\right) \text {. }
$$


OLS estimation by running a regression of $y_{1}$ on $z_{1}, y_{2}$ and $\hat{v}_{2}$ is called control function estimation, in the sense that inclusion of $\hat{v}_{2}$ in the structural equation controls for the endogeneity of $y_{2}$. The error term depends on the sampling error from $\left(\AA_{2}-\pi_{2}\right)$, unless $\rho_{1}=0$ (no endogeneity). Some algebra shows that function control estimates are identical to 2SLS estimates. When correctly specified, the control function (CF) estimator is more efficient than the IV estimator. However, its estimation depends on assumptions of linear relation between $u_{t}$ and $v_{t}$, what makes CF estimator less robust than the IV estimator, once it may not be consistent for different functional forms.

Now consider the following nonlinear model in which $y_{t}=g\left(x_{t} ; \psi_{0}\right)+u_{t}$ and $x_{t}=f\left(z_{t}\right)+v_{t}$. Assume that $E\left(u_{t} \mid x_{t}\right) \neq 0$ and that the relation between $u_{t}$ and $v_{t}$ is linear, i.e., $u_{t}=\alpha v_{t}+e_{t}$. We also assume also that $E\left(e_{t} \mid z_{t}\right)=0$ and $\left(e_{t} \mid x_{t}\right)=0$, that is more restrictive than the previous correlation hypothesis. Then we have

$$
\begin{gathered}
y_{z}=g\left(x_{t} ; \psi_{0}\right)+\alpha v_{t}+e_{t} \\
=g\left(x_{t} ; \psi_{0}\right)+\alpha\left(x_{t}-f\left(z_{t}\right)\right)+e_{t}
\end{gathered}
$$

This model can be estimated through simple nonlinear least-squares as well. The first step consists on the construction of a residual vector $\hat{v}$ from the nonparametric regression of $x_{t}$ on $z_{t}$. The second step runs the regression of $y_{t}$ on $g\left(x_{i} ; \psi_{0}\right)$ and $\hat{v}$. As before, CF estimator is more efficient than the IV estimator when correctly specified, but less robust to different functional forms.

The next session shows simulation results for LIML, NL2SLS and CF estimators for different data generating processes in order to evaluate theirs performances for different nonlinear models. 


\section{Simulation}

In this section, we use simulated data to evaluate the performance of the indicators for selected non-linear models. Simulated data was generated by using the exponential and logistic functions, that are widely used in the economic models as Count Data models and Smooth Transition Regression (STR) models, respectively. We present results for NL2SLS, LIML, and CF estimators (estimations of the control function parameter are omitted for simplicity). Histograms are provided in Appendix We make 1000 simulations with sample sizes $\mathrm{N}=100, \mathrm{~N}=250$ and $\mathrm{N}=500$. We constrain the parameters of the optimization problem on intervals of length $\mathrm{R}=8$. The first example is given by the following data generating process:

$$
\begin{aligned}
& y_{i}=\exp \left(\beta_{1}+\beta_{2} x_{1 i}+\beta_{3} x_{2 i}\right)+u_{i} \\
& x_{1 i}=w_{i}+e_{i} \\
& u_{i}=v_{i}+e_{i}
\end{aligned}
$$

In this example, $w_{i}, u_{i}, x_{2 i}$ and $v_{i}$ are standard normal iid random variables. $x_{1 i}$ is an endogenous variable and $w_{i}$ is an exogenous observed variable. The true parameter values are $\beta_{1}=2, \beta_{2}=-1, \beta_{3}=-0.5$. Results are shown on Table 1 . 
TABLE 1 - Estimation Results of Example1

\begin{tabular}{|c|c|c|c|c|c|c|}
\hline Parameter & Sample Size & Estimator & Bias & $\begin{array}{l}\text { Standard } \\
\text { Deviation }\end{array}$ & Skewness & Kurtosis \\
\hline \multirow{9}{*}{ BETA 1} & \multirow{3}{*}{100} & LIML & -0.4287 & 1.6921 & -3.3140 & 10.8972 \\
\hline & & NL2SLS & -0.3841 & 1.8838 & -3.6799 & 11.9317 \\
\hline & & $\mathrm{CF}$ & -0.2513 & 1.4215 & -4.3331 & 20.0472 \\
\hline & \multirow{3}{*}{250} & LIML & -0.3216 & 1.3761 & -3.6113 & 14.7775 \\
\hline & & NL2SLS & -0.1259 & 1.3926 & -5.4208 & 27.8049 \\
\hline & & $\mathrm{CF}$ & -0.1045 & 0.9790 & -5.3180 & 36.8406 \\
\hline & \multirow{3}{*}{500} & LIML & -0.1966 & 1.0665 & -4.2078 & 23.0809 \\
\hline & & NL2SLS & -0.0287 & 1.1154 & -6.9402 & 46.8110 \\
\hline & & $\mathrm{CF}$ & -0.0559 & 0.9913 & -5.6619 & 39.2679 \\
\hline \multirow{9}{*}{ BETA 2} & \multirow{3}{*}{100} & LIML & -0.0698 & 0.6219 & 1.3624 & 19.4416 \\
\hline & & NL2SLS & -0.0280 & 0.6759 & 0.4782 & 19.1284 \\
\hline & & $\mathrm{CF}$ & -0.0894 & 0.4515 & -3.7518 & 17.1932 \\
\hline & \multirow{3}{*}{250} & LIML & -0.0842 & 0.4410 & 0.6248 & 20.8432 \\
\hline & & NL2SLS & 0.0018 & 0.4553 & 0.7502 & 36.9238 \\
\hline & & $\mathrm{CF}$ & -0.0457 & 0.2730 & -3.5570 & 21.6015 \\
\hline & \multirow{3}{*}{500} & LIML & -0.0637 & 0.3566 & 1.6965 & 35.9536 \\
\hline & & NL2SLS & 0.0025 & 0.3283 & 1.2245 & 65.1663 \\
\hline & & $\mathrm{CF}$ & -0.0285 & 0.2526 & -4.1127 & 25.8734 \\
\hline \multirow{9}{*}{ BETA 3} & \multirow{3}{*}{100} & LIML & -0.1083 & 0.6512 & -3.9627 & 41.9855 \\
\hline & & NL2SLS & -0.1137 & 0.8022 & -3.3253 & 31.1256 \\
\hline & & $\mathrm{CF}$ & -0.0455 & 0.3748 & -3.6093 & 31.1749 \\
\hline & \multirow{3}{*}{250} & LIML & -0.0549 & 0.4242 & -1.1224 & 46.0618 \\
\hline & & NL2SLS & -0.0418 & 0.4596 & -5.0496 & 69.1375 \\
\hline & & $\mathrm{CF}$ & -0.0273 & 0.2846 & -4.0060 & 30.1992 \\
\hline & \multirow{3}{*}{500} & LIML & -0.0432 & 0.3152 & -7.2574 & 79.5337 \\
\hline & & NL2SLS & -0.0331 & 0.3653 & -9.2114 & 94.3324 \\
\hline & & $\mathrm{CF}$ & -0.0078 & 0.2571 & 0.6042 & 43.7625 \\
\hline
\end{tabular}

Results from Table 1 show that CF estimator performs better than NL2SLS and LIML estimators for all parameters and all sample sizes when standard deviation is observed. CF estimator also shows good performance on bias for parameters $\beta_{1}$ and $\beta_{3}$. LIML estimator has in most configurations lower standard deviation than NL2SLS estimator, but it shows usually higher bias. The results for standard deviation are according expectations, given that the CF estimator is more efficient than the other estimators. On Skewness, LIML estimator presents in most settings the lowest skewness measures in absolute values while FC estimator usually presents the higher measures. In most settings, the skewness values are negative. Kurtosis values vary among different settings, without showing a clear pattern among different settings. 
In the next example, we simulate data for the logistic function. The simulated data ha the following generating process:

$$
\begin{aligned}
& y_{i}=\beta_{1}+\beta_{2} x_{i}+\left(\beta_{3}+\beta_{4} x_{i}\right) \frac{1}{1+\exp \left(-\gamma\left(x_{i}-c\right)\right)}+u_{i} \\
& x_{i}=w_{i}+e_{i} \\
& u_{i}=w_{i}+v_{i}
\end{aligned}
$$

In this example, $w_{i}, u_{i}$ and $v_{i}$ are standard normal iid random variables. $x_{i}$ is the endogenous variable and $w_{i}$ is an exogenous observed variable. The true parameter values are $\beta_{1}=-0.2,, \beta_{2}=1.4, \beta_{3}=0.6, \beta_{4}=-2.3, \gamma=0.10$, $c=-2$. Each coordinate is a real interval with length $R=12$ centralized in the true parameter value. Results are shown on Table 2. 
TABLE 2 - Estimation Results of Example 2

\begin{tabular}{|c|c|c|c|c|c|c|}
\hline Parameter & Sample Size & Estimator & Bias & $\begin{array}{l}\text { Standard } \\
\text { Deviation }\end{array}$ & Skewness & Curtosis \\
\hline \multirow{9}{*}{ BETA 1} & \multirow{3}{*}{100} & LIML & 0.0547 & 0.3935 & -4.6685 & 74.1905 \\
\hline & & NL2SLS & 0.0173 & 1.2410 & -2.0484 & 35.2310 \\
\hline & & $\mathrm{CF}$ & -0.0065 & 0.1633 & -3.8999 & 41.4142 \\
\hline & \multirow{3}{*}{250} & LIML & 0.0813 & 0.1882 & 0.5200 & 3.8301 \\
\hline & & NL2SLS & -0.0724 & 1.1717 & -6.4681 & 51.0804 \\
\hline & & $\mathrm{CF}$ & 0.0221 & 0.0737 & -0.0116 & 0.0628 \\
\hline & \multirow{3}{*}{500} & LIML & 0.0572 & 0.1220 & 0.0102 & 1.1245 \\
\hline & & NL2SLS & -0.1198 & 0.9356 & -6.6804 & 54.2414 \\
\hline & & $\mathrm{CF}$ & 0.0213 & 0.0509 & 0.0233 & 0.0392 \\
\hline \multirow{9}{*}{ BETA 2} & \multirow{3}{*}{100} & LIML & 0.0710 & 0.3074 & -0.5326 & 2.1532 \\
\hline & & NL2SLS & 0.0664 & 0.6767 & 0.1401 & 22.3509 \\
\hline & & $\mathrm{CF}$ & -0.0061 & 0.1874 & -0.9391 & 2.9145 \\
\hline & \multirow{3}{*}{250} & LIML & 0.0725 & 0.1837 & -0.5073 & 2.7746 \\
\hline & & NL2SLS & 0.0108 & 0.5039 & -4.3014 & 30.9611 \\
\hline & & $\mathrm{CF}$ & 0.0151 & 0.1023 & -0.2612 & 0.3338 \\
\hline & \multirow{3}{*}{500} & LIML & 0.0570 & 0.1193 & -0.4182 & 1.5387 \\
\hline & & NL2SLS & -0.0242 & 0.3933 & -5.1687 & 42.3855 \\
\hline & & $\mathrm{CF}$ & 0.0211 & 0.0697 & -0.0003 & -0.0817 \\
\hline \multirow{9}{*}{ BETA 3} & \multirow{3}{*}{100} & LIML & -0.0603 & 6.9763 & -0.2306 & -0.7602 \\
\hline & & NL2SLS & -0.0118 & 8.2506 & -0.0553 & -1.1953 \\
\hline & & $\mathrm{CF}$ & 2.8607 & 3.9409 & -0.7023 & 1.6471 \\
\hline & \multirow{3}{*}{250} & LIML & 0.0406 & 5.2844 & -0.4565 & 0.3627 \\
\hline & & NL2SLS & 0.6276 & 6.9347 & -0.1694 & -0.5846 \\
\hline & & $\mathrm{CF}$ & 2.7364 & 2.2395 & -0.2070 & 1.3943 \\
\hline & \multirow{3}{*}{500} & LIML & 0.8264 & 4.0105 & -0.5621 & 1.9981 \\
\hline & & NL2SLS & 1.7073 & 5.5606 & -0.2560 & 0.2223 \\
\hline & & $\mathrm{CF}$ & 2.6687 & 1.5686 & -0.2180 & 0.1117 \\
\hline \multirow{9}{*}{ BETA 4} & \multirow{3}{*}{100} & LIML & 0.0341 & 2.6524 & 0.2261 & -0.0584 \\
\hline & & NL2SLS & 0.1950 & 3.0869 & 0.1787 & -0.4619 \\
\hline & & $\mathrm{CF}$ & -0.9987 & 1.4406 & 0.4215 & 1.9739 \\
\hline & \multirow{3}{*}{250} & LIML & -0.0298 & 1.9751 & 0.3975 & 0.8144 \\
\hline & & NL2SLS & -0.0346 & 2.4714 & 0.1414 & -0.0404 \\
\hline & & $\mathrm{CF}$ & -0.9409 & 0.8094 & -0.0992 & 1.9126 \\
\hline & \multirow{3}{*}{500} & LIML & -0.2741 & 1.4639 & 0.5450 & 2.2567 \\
\hline & & NL2SLS & -0.3741 & 1.9320 & 0.3595 & 0.8724 \\
\hline & & $\mathrm{CF}$ & -0.8972 & 0.5523 & 0.0578 & 0.2211 \\
\hline \multirow{9}{*}{ GAMMA } & \multirow{3}{*}{100} & LIML & 28.0135 & 48.1874 & 1.2298 & -0.2753 \\
\hline & & NL2SLS & 70.0454 & 56.9214 & -0.3318 & -1.8067 \\
\hline & & $\mathrm{CF}$ & 23.2848 & 46.1554 & 1.4868 & 0.4017 \\
\hline & & LIML & 10.2422 & 33.3717 & 2.7430 & 6.0586 \\
\hline & 250 & NL2SLS & 66.4734 & 58.3630 & -0.2284 & -1.8807 \\
\hline & & $\mathrm{CF}$ & 4.1552 & 22.7637 & 4.3923 & 18.9138 \\
\hline & & LIML & 3.9727 & 21.7184 & 4.4426 & 19.9778 \\
\hline & 500 & NL2SLS & 64.6422 & 58.3556 & -0.1730 & -1.8958 \\
\hline & & $\mathrm{CF}$ & -0.3235 & 9.4305 & 9.7049 & 112.0940 \\
\hline & & LIML & 0.2997 & 0.3086 & 2.2638 & 13.8849 \\
\hline & 100 & NL2SLS & 0.5769 & 0.6285 & 2.0932 & 6.0902 \\
\hline & & $\mathrm{CF}$ & 0.2521 & 0.2500 & 0.9479 & 1.6021 \\
\hline & & LIML & 0.2333 & 0.2028 & 2.4290 & 12.9883 \\
\hline C & 250 & NL2SLS & 0.5300 & 0.5530 & 2.2025 & 6.5778 \\
\hline & & $\mathrm{CF}$ & 0.1972 & 0.1428 & 0.5322 & 1.0059 \\
\hline & & LIML & 0.2080 & 0.1367 & 2.0720 & 11.5628 \\
\hline & 500 & NL2SLS & 0.4708 & 0.4801 & 2.3090 & 7.8329 \\
\hline & & CF & 0.1900 & 0.1026 & 0.0479 & -0.4559 \\
\hline
\end{tabular}


Results from Table 2 show that $\mathrm{CF}$ estimator has again a better performance on standard deviation than NL2SLS and LIML estimators for all parameters and sample sizes. CF estimator shows good performance on bias for parameters $\beta_{1}$, $\beta_{2}, \gamma$, and $c$. LIML estimator has better performance on bias for parameters $\beta_{3}$ and $\beta_{4}$ than CF and NL2SLS estimators. The results for standard deviation are according expectations, given that the $\mathrm{CF}$ estimator is more efficient than the others. This result holds from the previous example due to the linear relation between the endogenous variable and the instrumental variable. The next example changes this linear relationship. Therefore, we should expect that CF estimator will not be the more efficient anymore. Performance on skewness differ among estimators depending on the estimated parameter. NL2SLS has better results for gamma and $\mathrm{CF}$ has better results for c. For other parameters, there is not an estimator that is consistent closer to zero than the others. On kurtosis, there is no estimator that is consistently closer to zero than other estimators. It only happens on the estimation of the parameter $\mathrm{c}$, in which FC estimator shows results closer to zero for all sample sizes.

In the third example, 1000 simulated data have been generated with the same specifications as the previous example, except in the data generating process of the endogenous variable. In this example $x_{1}$ is a quadratic function of the exogenous variable $w_{i}$ :

$$
\begin{aligned}
& y_{i}=\beta_{1}+\beta_{2} x_{i}+\left(\beta_{3}+\beta_{4} x_{i}\right) \frac{1}{1+\exp \left(-\gamma\left(x_{i}-c\right)\right)}+u_{i} \\
& x_{i}=-2+4 w_{i}^{2}+e_{i} \\
& u_{i}=w_{i}+v_{i}
\end{aligned}
$$

Simulation results are presented on Table 3: 
TABLE 3 - Estimation Results of Example 3

\begin{tabular}{|c|c|c|c|c|c|c|}
\hline Parameter & Sample Size & Estimator & Bias & $\begin{array}{l}\text { Standard } \\
\text { Deviation }\end{array}$ & Skewness & Curtosis \\
\hline \multirow{9}{*}{ BETA 1} & \multirow{3}{*}{100} & LIML & 0.3192 & 1.3920 & 0.9280 & 11.1951 \\
\hline & & NL2SLS & 0.4787 & 3.3778 & -0.2695 & 3.9673 \\
\hline & & $\mathrm{CF}$ & 0.4620 & 0.4057 & -5.9099 & 110.1470 \\
\hline & \multirow{3}{*}{250} & LIML & 0.3146 & 1.1494 & 1.2199 & 19.5811 \\
\hline & & NL2SLS & 0.4262 & 4.1899 & -0.3713 & 2.1552 \\
\hline & & $\mathrm{CF}$ & 0.4340 & 0.2139 & 0.5118 & 0.2970 \\
\hline & \multirow{3}{*}{500} & LIML & 0.1704 & 0.7037 & 3.4992 & 21.1529 \\
\hline & & NL2SLS & 0.2287 & 4.9284 & -0.4562 & 1.1509 \\
\hline & & CF & 0.3990 & 0.1485 & 0.4925 & 0.7266 \\
\hline \multirow{9}{*}{ BETA 2} & \multirow{3}{*}{100} & LIML & 0.2731 & 1.1421 & 1.1509 & 9.7344 \\
\hline & & NL2SLS & 0.4207 & 2.2282 & 0.1232 & 2.5026 \\
\hline & & $\mathrm{CF}$ & 0.6061 & 1.5012 & 1.8964 & 42.9453 \\
\hline & \multirow{3}{*}{250} & LIML & 0.2758 & 0.9367 & 2.5995 & 17.0629 \\
\hline & & NL2SLS & 0.5149 & 2.7022 & 0.1816 & 2.0787 \\
\hline & & $\mathrm{CF}$ & 0.4680 & 1.1482 & -1.0367 & 70.2909 \\
\hline & \multirow{3}{*}{500} & LIML & 0.1437 & 0.5919 & 3.4469 & 19.7187 \\
\hline & & NL2SLS & 0.6203 & 2.9106 & 0.1225 & 1.0238 \\
\hline & & $\mathrm{CF}$ & 0.4829 & 1.3803 & 2.1850 & 45.3437 \\
\hline \multirow{9}{*}{ BETA 3} & \multirow{3}{*}{100} & LIML & -0.6854 & 2.5421 & -0.8842 & 6.3821 \\
\hline & & NL2SLS & -0.8770 & 4.7317 & 0.1104 & 1.5145 \\
\hline & & $\mathrm{CF}$ & -0.1971 & 0.7941 & 1.1515 & 16.5548 \\
\hline & \multirow{3}{*}{250} & LIML & -0.5733 & 1.9576 & -2.0341 & 13.6920 \\
\hline & & NL2SLS & -0.7401 & 5.2045 & 0.3080 & 1.0235 \\
\hline & & $\mathrm{CF}$ & -0.2117 & 0.4489 & 0.0494 & 0.7688 \\
\hline & \multirow{3}{*}{500} & LIML & -0.3110 & 1.2620 & -3.6649 & 21.2593 \\
\hline & & NL2SLS & -0.4731 & 5.8241 & 0.3045 & 0.3829 \\
\hline & & $\mathrm{CF}$ & -0.2475 & 0.2949 & -0.1751 & 0.8656 \\
\hline \multirow{9}{*}{ BETA 4} & \multirow{3}{*}{100} & LIML & -0.2478 & 1.0812 & -1.2292 & 10.5253 \\
\hline & & NL2SLS & -0.3945 & 2.1528 & -0.1468 & 2.7572 \\
\hline & & $\mathrm{CF}$ & -0.5104 & 0.1947 & -0.3300 & 1.0763 \\
\hline & \multirow{3}{*}{250} & LIML & -0.2607 & 0.8944 & -2.5864 & 17.3566 \\
\hline & & NL2SLS & -0.4972 & 2.6511 & -0.2101 & 2.2255 \\
\hline & & $\mathrm{CF}$ & -0.4851 & 0.1254 & -0.6105 & 0.5080 \\
\hline & \multirow{3}{*}{500} & LIML & -0.1359 & 0.5636 & -3.3865 & 19.3691 \\
\hline & & NL2SLS & -0.6071 & 2.8628 & -0.1400 & 1.1050 \\
\hline & & $\mathrm{CF}$ & -0.4622 & 0.0844 & -0.3495 & 0.5054 \\
\hline \multirow{9}{*}{ GAMMA } & \multirow{3}{*}{100} & LIML & 32.7788 & 47.8411 & 0.9720 & -0.7483 \\
\hline & & NL2SLS & 53.1008 & 57.3207 & 0.2256 & -1.8674 \\
\hline & & $\mathrm{CF}$ & 32.0854 & 51.5647 & 0.9352 & -0.9275 \\
\hline & & LIML & 18.6800 & 38.9737 & 1.9443 & 2.2271 \\
\hline & 250 & NL2SLS & 73.3277 & 56.9283 & -0.4611 & -1.7160 \\
\hline & & $\mathrm{CF}$ & 12.8033 & 39.4727 & 2.1934 & 3.1185 \\
\hline & & LIML & 8.3095 & 25.7861 & 3.5859 & 12.2833 \\
\hline & 500 & NL2SLS & 78.6949 & 55.0424 & -0.6614 & -1.4755 \\
\hline & & CF & 0.2037 & 20.2142 & 5.1424 & 26.7201 \\
\hline & & LIML & 0.0667 & 0.3737 & 2.8003 & 12.2197 \\
\hline & 100 & NL2SLS & 0.3650 & 0.8644 & 1.5611 & 2.3504 \\
\hline & & $\mathrm{CF}$ & 0.4142 & 0.6525 & 1.6285 & 1.7806 \\
\hline & & LIML & 0.0269 & 0.2314 & 7.4027 & 93.5865 \\
\hline $\mathrm{C}$ & 250 & NL2SLS & 0.6844 & 1.1556 & 1.4053 & 1.6060 \\
\hline & & CF & 0.2508 & 0.4282 & 2.6609 & 6.5832 \\
\hline & & LIML & 0.0063 & 0.1089 & 4.1612 & 43.3998 \\
\hline & 500 & NL2SLS & 0.9871 & 1.3393 & 1.1059 & 0.4112 \\
\hline & & $\mathrm{CF}$ & 0.1331 & 0.1657 & 4.9338 & 40.7142 \\
\hline
\end{tabular}


Results on Table 3 show now that CF estimator has better performance on standard deviation only for parameter $\beta_{1}, \beta_{3}$, and $\beta_{4}$. LIML estimator overcomes the performance of the $\mathrm{CF}$ estimator on standard deviation for parameters $\beta_{2}, \gamma$, and $c$ for almost all simple sizes. LIML estimator presents lower bias for parameters $\beta_{1}, \beta_{2}, \beta_{4}$, and $c$ while CF estimtor has lower bias for $\beta_{3}$ and $\gamma$. Differently from previous examples, $\mathrm{CF}$ estimator has not a better performance over the other estimators on standard deviation, particularly the LIML estimator. This may occur because the relationship of the endogenous variable and the instrumental variable is not linear anymore. Results show, however, that either LIML or CF estimators perform better than the NL2SLS estimator. Skewness results for NL2SLS estimator is closer to zero than the other estimators in all settings for all parameters. Kurtosis results for NL2SLS are the closest to zero for all parameters and sample sizes. Its kurtosis remains steady among the different settings, without reaching very large values. 


\section{Application}

In this section we estimate a nonlinear Phillips curve for Brazilian economy using a Smooth Transition Regression (STR) model as in Areosa (2011). The estimated model has the following equation:

$$
\begin{gathered}
\pi_{t}=\beta_{o}^{L}+\beta_{1}^{L} \pi_{t-1}+\beta_{2}^{L} x_{t-1}+\beta_{3}^{L} E_{t} \pi_{t+1}+ \\
+\left(\beta_{o}^{N}+\beta_{1}^{N} \pi_{t-1}+\beta_{2}^{N} x_{t-1}+\beta_{3}^{N} E_{t} \pi_{t+1}\right) \frac{1}{1+\exp \left(-\gamma\left(\sigma_{t}^{M}-c\right)\right.} .
\end{gathered}
$$

The instruments set is $w_{t}=\left[\pi_{t-1}, x_{t-1}, E_{t-1} \pi_{t}, \tilde{\sigma}_{t-1}^{\pi}, \Delta i_{t-1}\right]$, where $\pi_{t}$ is the inflation rate, $x_{t}$ is the output gap, $E_{t} \pi_{t+1}$ is the inflation expectation, $\tilde{\sigma}_{t}^{\pi}$ is the standard deviation of the inflation expectation and $i_{t}$ is the interest rate. The set of instruments is obtained from the moment condition derived from the rational expectations hypothesis. Data is obtained from IBGE and Brazilian Central Bank. Inflation rate corresponds to annualized consumers price index (IPCA) and interest rate corresponds to monthly average SELIC rate.

In this application it is assumed that each coordinate of $\Psi$ is centered at $(0,0290,0,3310,0,0040,0,8440,0,0160,-0,2250,0,8950,2,3380,18,1,0600)$ with length $(8,8,8,8,8,8,8,8,80,8)$. The parameter $\alpha$ of the control function is centered at 1 with interval length equal to 5 . Results are shown in Table 4 .

Table 4 shows estimation results for LIML, NL2SLS, and CF estimators. 
TABLE 4 - Estimation Results for STR Model

\begin{tabular}{|c|c|c|c|c|}
\hline PARAMETER & OLS & LIML & NL2SLS & $\mathrm{CF}$ \\
\hline$\beta_{0}^{L}$ & $\begin{array}{c}0.0282 \\
(11.747)\end{array}$ & $\begin{array}{c}0.057 \\
(0.007)\end{array}$ & $\begin{array}{c}0.059 \\
(11.747)\end{array}$ & $\begin{array}{c}0.008 \\
(11.747)\end{array}$ \\
\hline$\beta_{1}^{L}$ & $\begin{array}{l}0.4145 \\
(0.956)\end{array}$ & $\begin{array}{l}-0.166 \\
(0.111)\end{array}$ & $\begin{array}{l}-0.203 \\
(0.903)\end{array}$ & $\begin{array}{c}0.565 \\
(0.956)\end{array}$ \\
\hline$\beta_{2}^{L}$ & $\begin{array}{c}-0.0237 \\
(0.477)\end{array}$ & $\begin{array}{c}0.002 \\
(0.084)\end{array}$ & $\begin{array}{c}0.006 \\
(0.429)\end{array}$ & $\begin{array}{c}-0.302 \\
(0.477)\end{array}$ \\
\hline$\beta_{3}^{L}$ & $\begin{array}{l}0.8803 \\
(0.209)\end{array}$ & $\begin{array}{c}1.423 \\
(0.587)\end{array}$ & $\begin{array}{c}1.471 \\
(0.207)\end{array}$ & $\begin{array}{c}0.293 \\
(0.209)\end{array}$ \\
\hline$\beta_{0}^{N}$ & $\begin{array}{c}0.04 \\
(4.657)\end{array}$ & $\begin{array}{c}0.09 \\
(0.033)\end{array}$ & $\begin{array}{c}0.099 \\
(3.422)\end{array}$ & $\begin{array}{c}0.18 \\
(2.509)\end{array}$ \\
\hline$\beta_{1}^{N}$ & $\begin{array}{c}-0.3854 \\
(0.650)\end{array}$ & $\begin{array}{c}0.193 \\
(0.235)\end{array}$ & $\begin{array}{c}0.235 \\
(0.605)\end{array}$ & $\begin{array}{c}-0.869 \\
(0.469)\end{array}$ \\
\hline$\beta_{2}^{N}$ & $\begin{array}{c}1.685 \\
(0.180)\end{array}$ & $\begin{array}{c}2.599 \\
(0.459)\end{array}$ & $\begin{array}{c}2.663 \\
(0.155)\end{array}$ & $\begin{array}{c}3.397 \\
(0.088)\end{array}$ \\
\hline$\beta_{3}^{N}$ & $\begin{array}{c}1.591 \\
(0.191)\end{array}$ & $\begin{array}{c}0.201 \\
(1.013)\end{array}$ & $\begin{array}{l}-0.013 \\
(0.184)\end{array}$ & $\begin{array}{c}1.933 \\
(0.129)\end{array}$ \\
\hline$\gamma$ & $\begin{array}{l}17.9891 \\
(0.002)\end{array}$ & $\begin{array}{l}17.954 \\
(12.4)\end{array}$ & $\begin{array}{l}58 \\
(0)\end{array}$ & $\begin{array}{c}0.948 \\
(0.477)\end{array}$ \\
\hline$c$ & $\begin{array}{l}1.4656 \\
(0.653)\end{array}$ & $\begin{array}{c}1.692 \\
(0.064)\end{array}$ & $\begin{array}{c}1.745 \\
(0.762)\end{array}$ & $\begin{array}{c}3.234 \\
(0.204)\end{array}$ \\
\hline$\lambda$ & & & & $\begin{array}{c}-0.014 \\
(4.497)\end{array}$ \\
\hline
\end{tabular}

The estimated parameters partially differ from the economic theory presented in Areosa (2011) and the values are similar to the obtained in the paper only for some parameters. Results of Table 4 show that $\beta_{1}^{L}$ is not positive and significant for any estimator while $\beta_{3}^{L}$ is positive and significant for almost all estimators. $\beta_{2}^{N}, \beta_{3}^{N}$ and $c$, on the other hand, are positive and significant for most estimators. It's interesting to notice that with exception from $\beta_{1}^{L}$, all estimations from $\mathrm{CF}$ estimator are in line with the economic theory. Moreover, for the parameters $\beta_{2}^{N}, \beta_{3}^{C}$ and $c$, the CF estimator presented the lowest standard errors. However, the estimation of $\lambda$ is not significant. 


\section{Conclusion}

The aim of this paper is to compare the performance of the two-stage nonlinear least-squares (NL2SLS) estimator, the nonlinear limited information maximum likelihood (LIML) estimator and the Control Function (CF) estimator for specific families of nonlinear functions. For simulated data on examples 1 and 2, the CF estimator performed better than the other estimators for standard deviation in settings with different sample sizes, followed by the LIML estimator. This result was expected due to the linear relation between the endogenous variable and the instrumental variable. On example 3, there was a nonlinear relation between the instrumental variable and the endogenous variable. Therefore, it was not straightforward to determine what estimator has presented the best performance. However, results have shown that both $\mathrm{CF}$ estimator and LIML estimator performed better than the NL2SLS estimator. The use of the STR model to estimate a nonlinear Phillips curve for the Brazilian economy showed that estimation results for LIML and CF estimators are in line with the ones previously estimated by Areosa et al. and corroborate results underlined by the economic theory. 


\section{References}

Amemiya, Takeshi. The nonlinear two-stage least-squares estimator. Journal of Econometrics, 2(2):105-110, 1974.

Amemiya, Takeshi. The nonlinear limited-information maximum-likelihood estimator and the modified nonlinear two-stage least-squares estimator. Journal of Econometrics, 3(4):375-386, 1975.

Areosa, W.D., McAleer M., Medeiros, M.C.. Moment-based estimation of smooth transition regression models with endogenous variables. Journal of Econometrics, 165(1):100-111, 2011.

Chamberlain, G.. Asymptotic efficiency in estimation with conditional moment restrictions. Journal of Econometrics, 34(3):305-334, 1987.

Imbens, Guido, and Wooldridge, J.. Control Function and Related Methods. What's New in Econometrics (lecture for NBER), 2007.

Whitney, W.K.. Efficient instrumental variables estimation of nonlinear models. Econometrica, 58(4):pp. 809-837, 1990. 


\section{Appendix}

FIGURE 1 - Histograms of Example $1\left(\beta_{1}\right)$

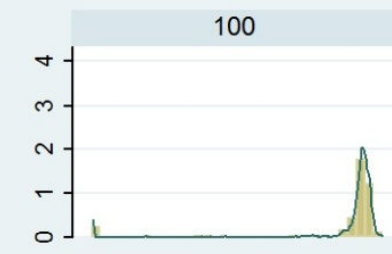

250

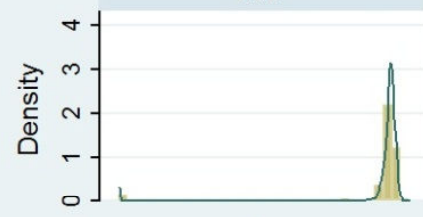

500

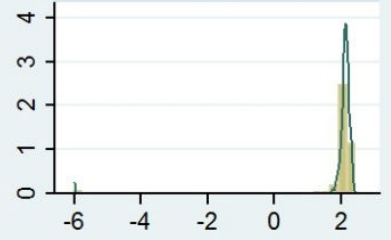

BETA 1 (NL2SLS)

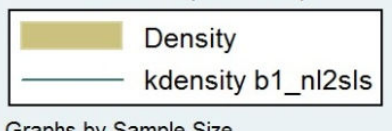

Graphs by Sample Size
100

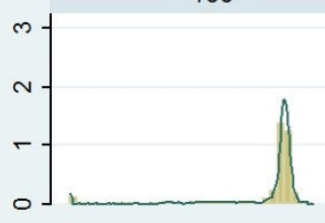

250

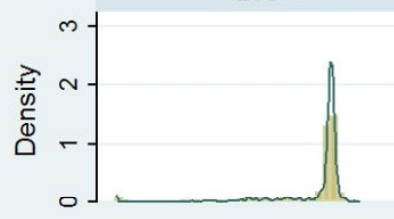

500

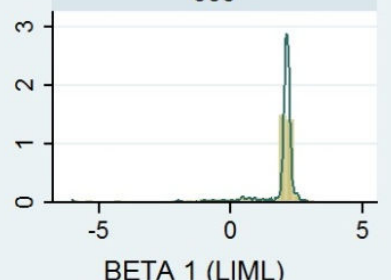

Density

kdensity b1_liml

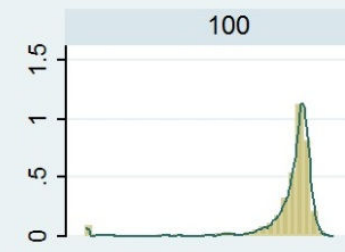

250

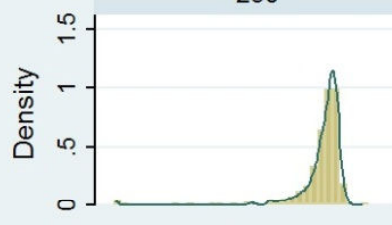

500

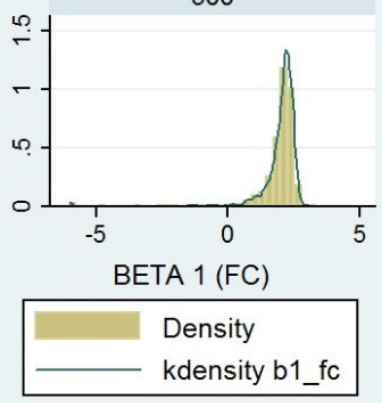


FIGURE 2 - Histograms of Example 1

$\left(\beta_{2}\right)$

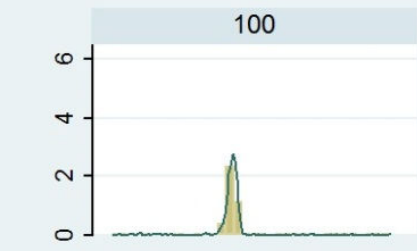

250

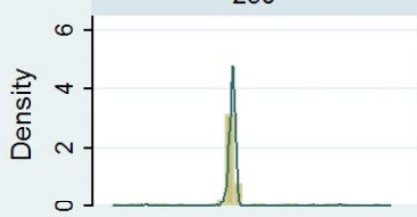

500

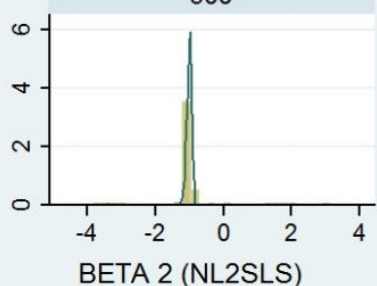

Density

kdensity b2 nl2sls

Graphs by Sample Size

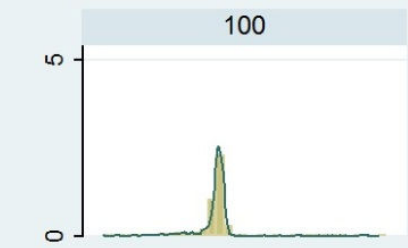

250

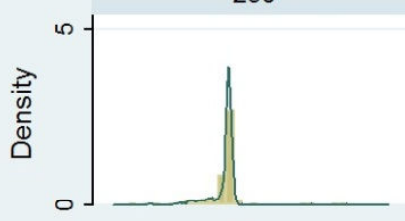

500

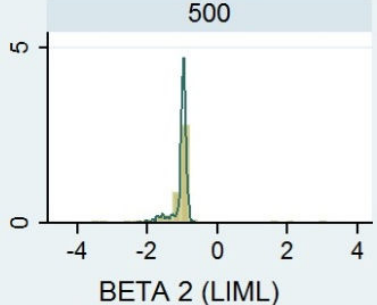

Density

kdensity b2_liml
100

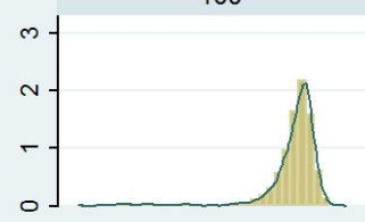

250

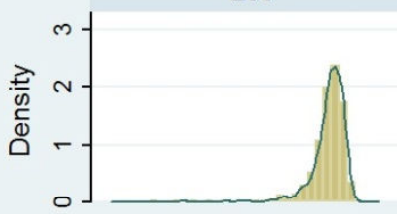

500

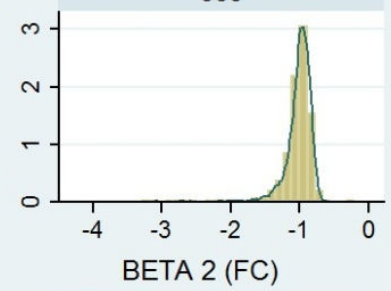

Density

kdensity b2_fc 
FIGURE 3 - Histograms of Example $1\left(\beta_{3}\right)$

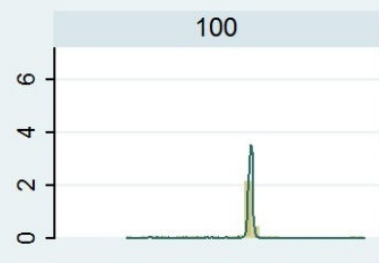

250

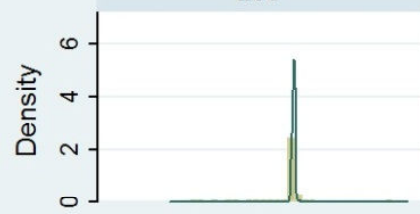

500

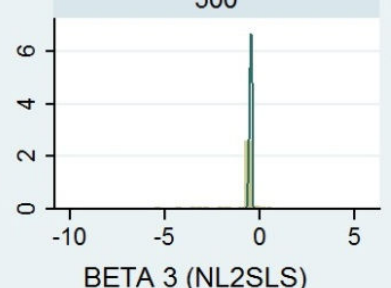

Density

kdensity b3_nl2sls

Graphs by Sample Size
100

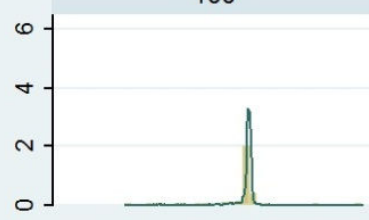

250

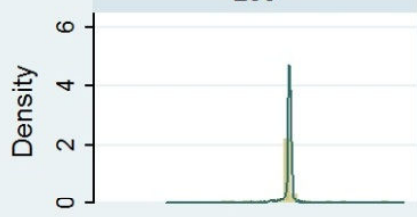

500

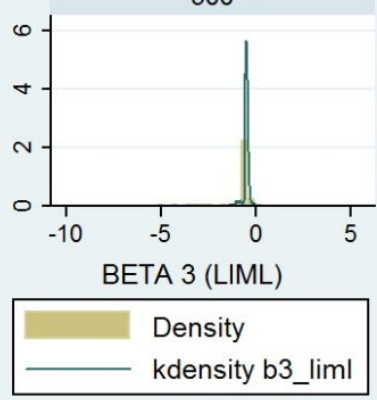

100

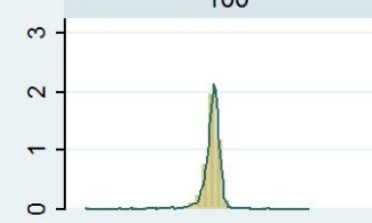

250

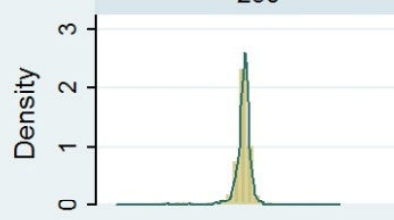

500

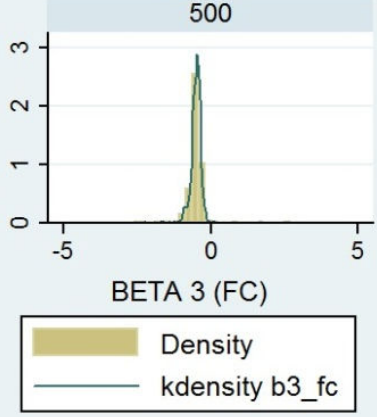


FIGURE 4 - Histograms of Example $2\left(\beta_{1}\right)$

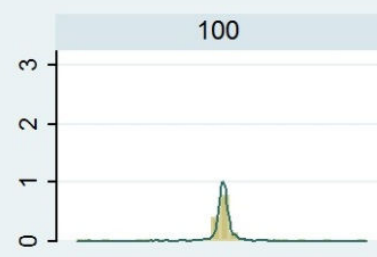

250

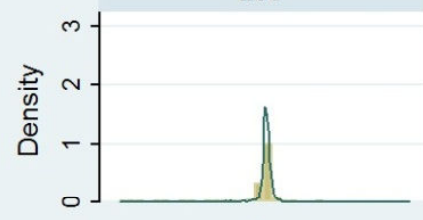

500

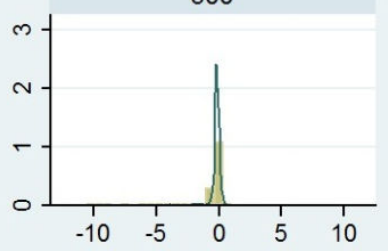

BETA 1 (NL2SLS)

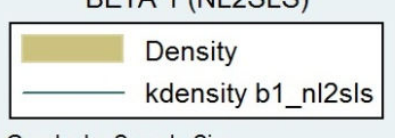

Graphs by Sample Size
100

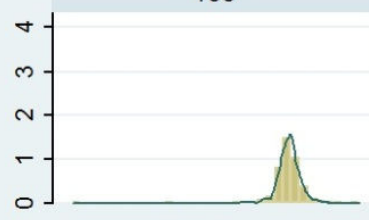

250

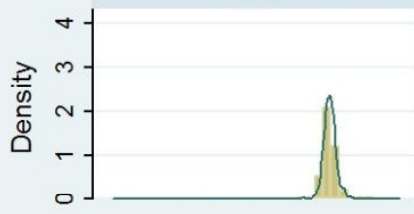

500

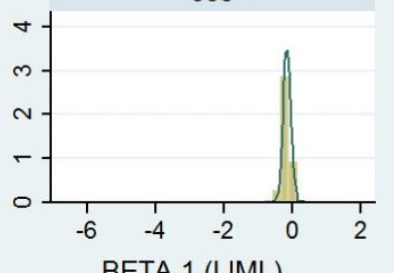

BETA 1 (LIML)

Density kdensity b1_liml
100

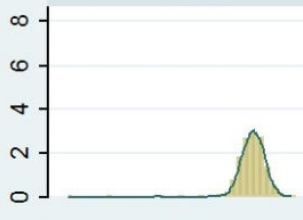

250
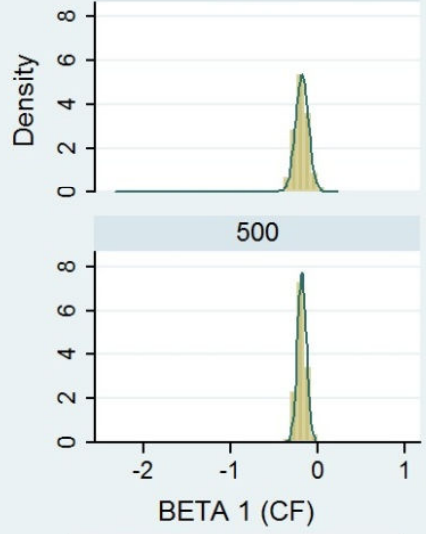

Density kdensity b1_fc 
FIGURE 5 - Histograms of Example $2\left(\beta_{2}\right)$

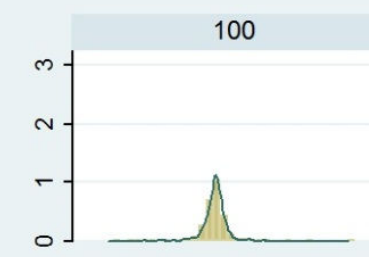

250

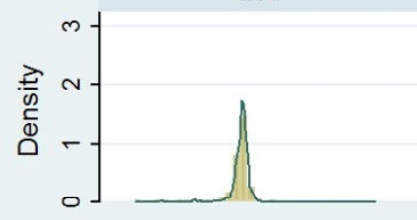

500
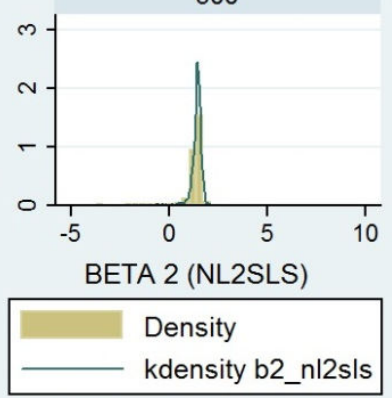

Graphs by Sample Size
100

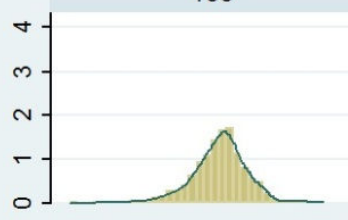

250

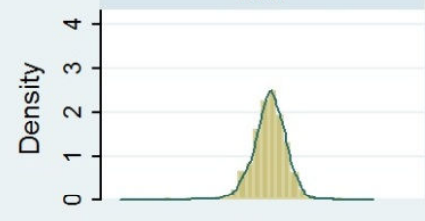

500

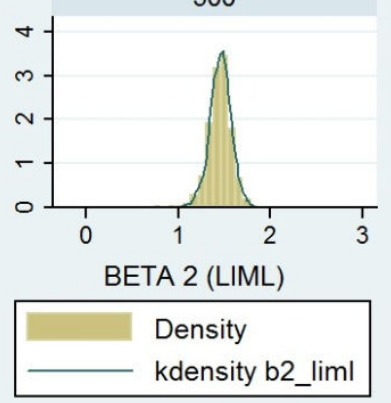

100

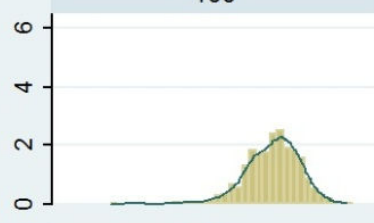

250

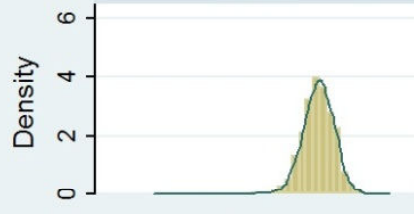

500

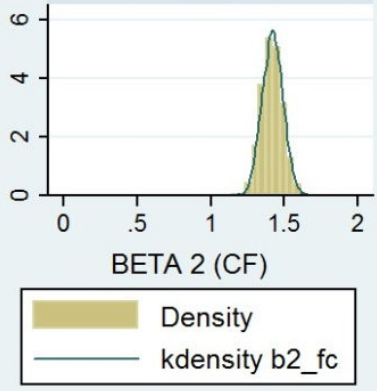


FIGURE 6 - Histograms of Example $2\left(\beta_{3}\right)$

100

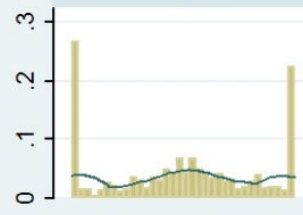

250

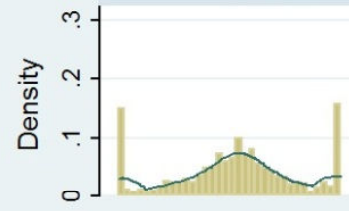

500

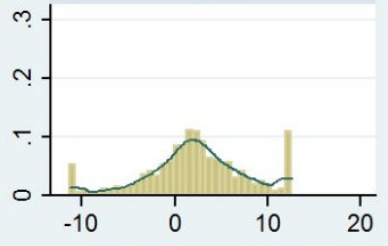

BETA 3 (NL2SLS)

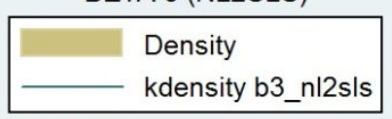

Graphs by Sample Size
100

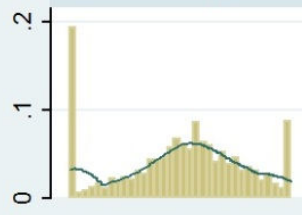

250

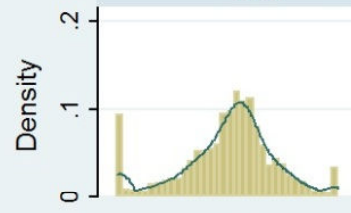

500

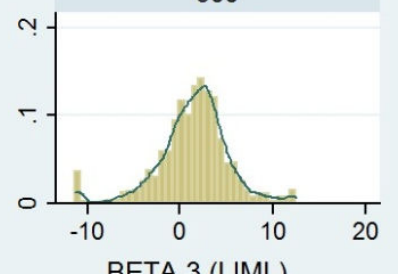

BETA 3 (LIML)

Density

kdensity b3_liml
100

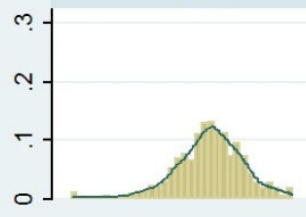

250

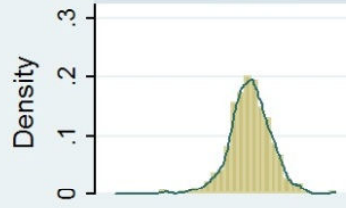

500

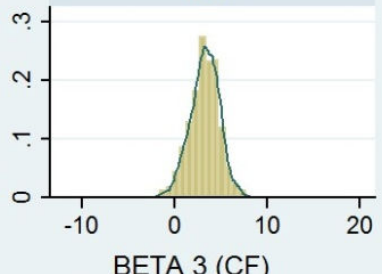

Density kdensity b3_fc 
FIGURE 7 - Histograms of Example $2\left(\beta_{4}\right)$

100

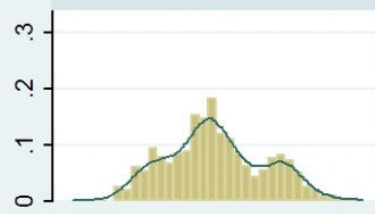

250

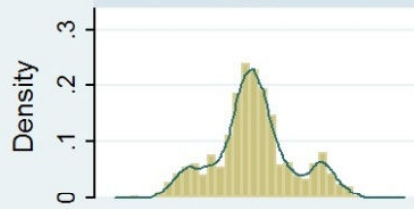

500

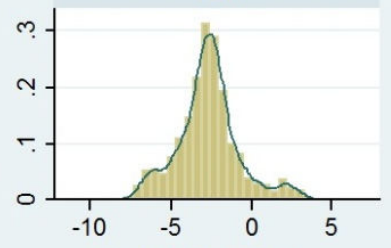

BETA 4 (NL2SLS)

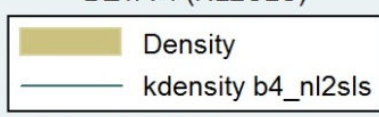

Graphs by Sample Size
100

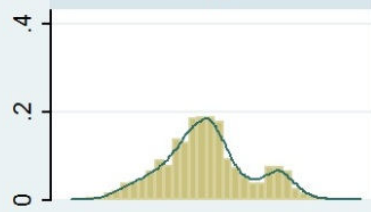

250

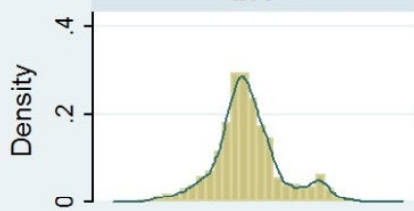

500

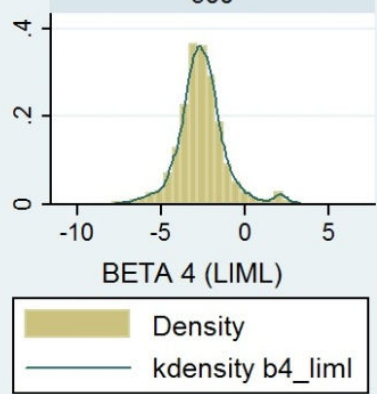

100

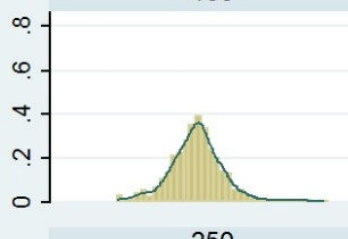

250

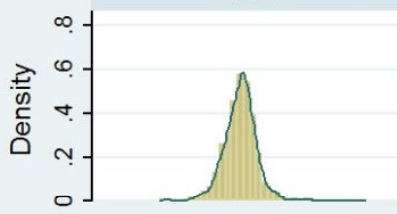

500

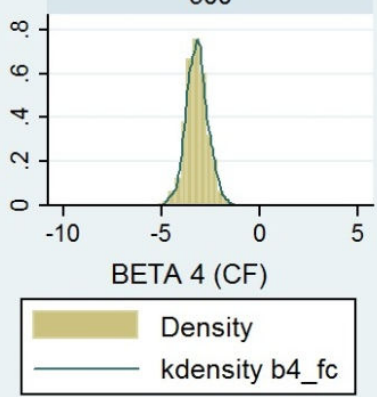


FIGURE 8 - Histograms of Example $2(\gamma)$

100

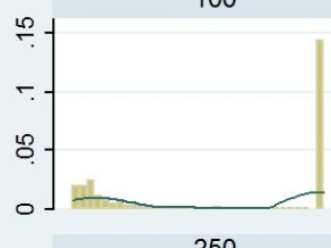

250
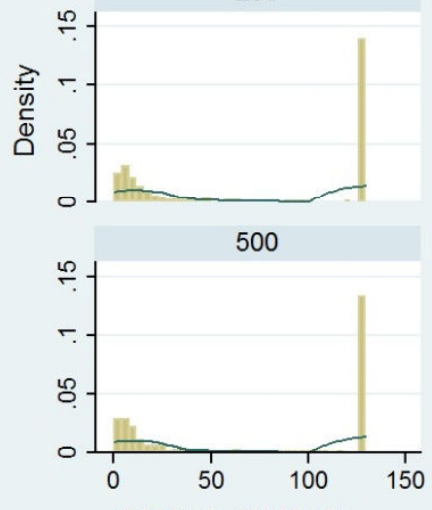

GAMMA (NL2SLS)

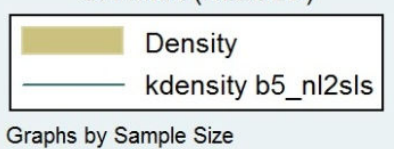

100

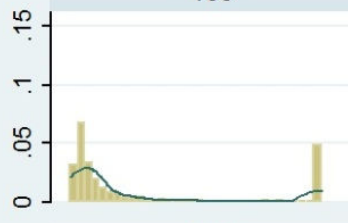

250

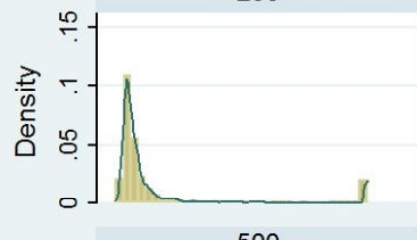

500

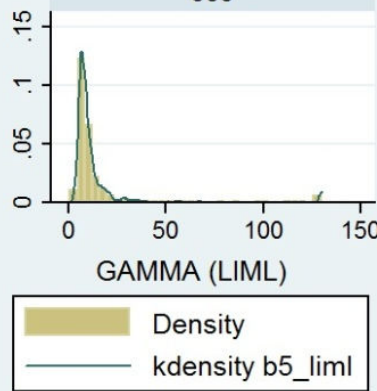

100

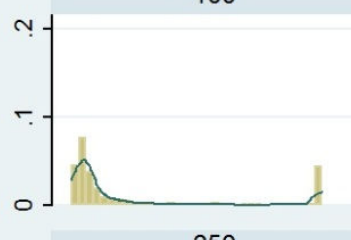

250
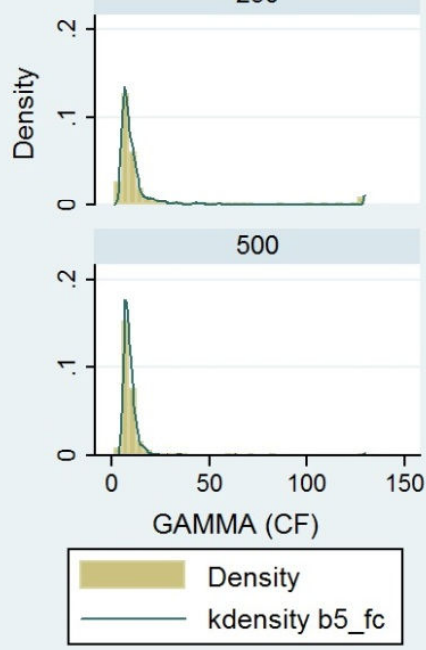
FIGURE 9 - Histograms of Example 2 (c)

100

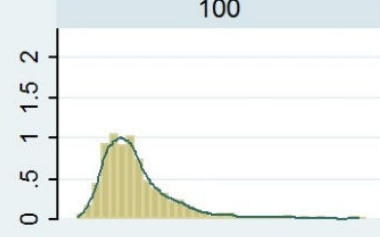

250

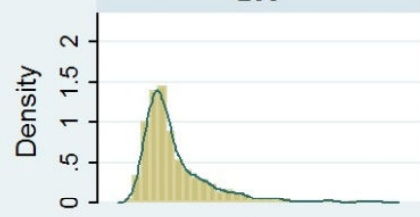

500

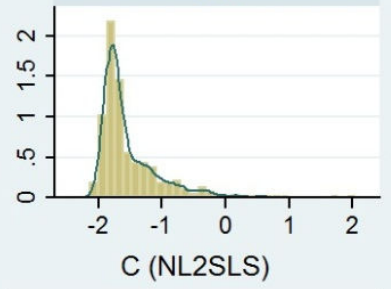

Density

kdensity b6_nl2sls
100

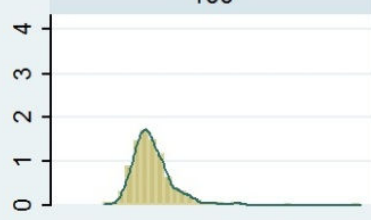

250

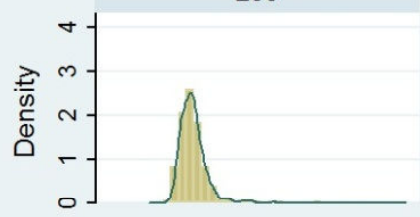

500

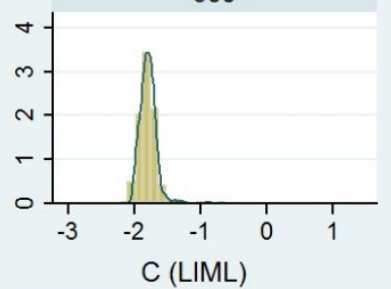

Density

kdensity b6_liml

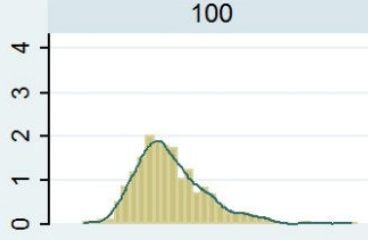

250

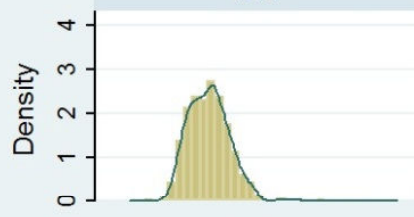

500

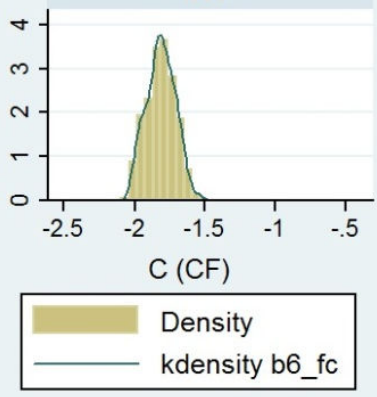

Graphs by Sample Size 
FIGURE 10 - Histograms of Example $3\left(\beta_{1}\right)$

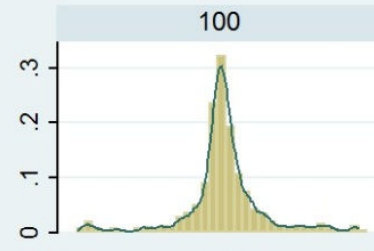

250

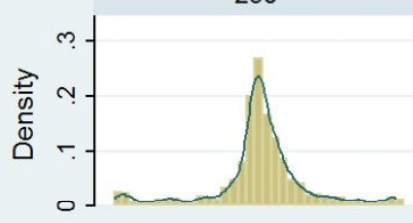

500

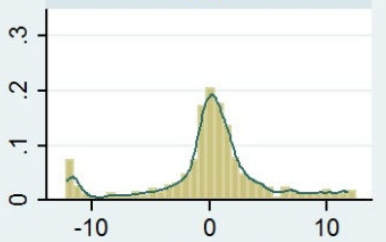

BETA 1 (NL2SLS)

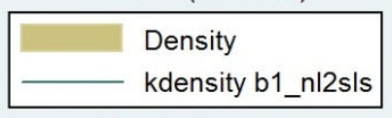

Graphs by Sample Size
100

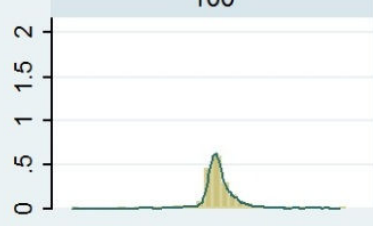

250

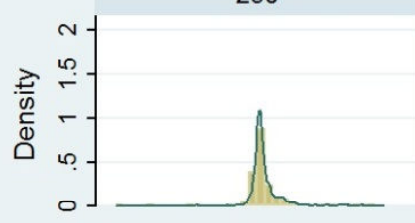

500

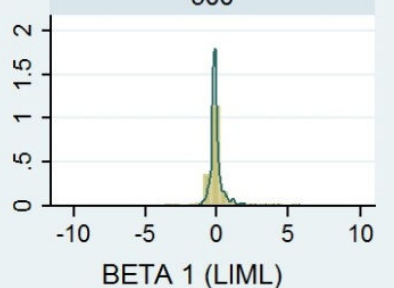

Density

kdensity b1_liml
100

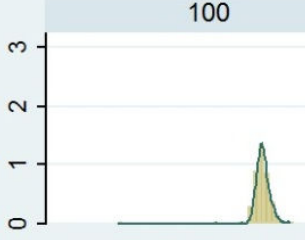

250

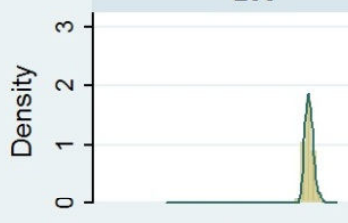

500

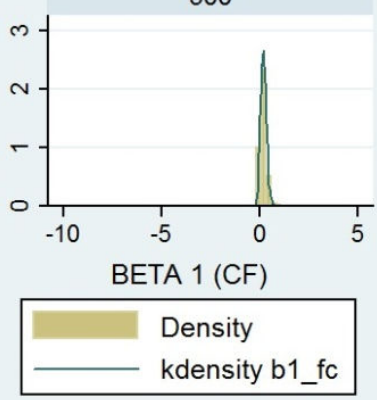


FIGURE 11 - Histograms of Example $3\left(\beta_{2}\right)$

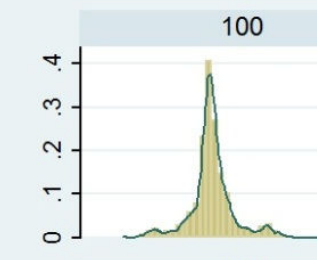

250

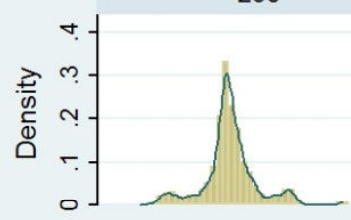

500

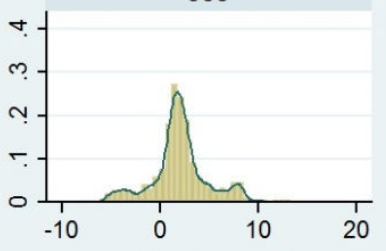

BETA 2 (NL2SLS)

Density

kdensity b2_nl2sls

Graphs by Sample Size
100

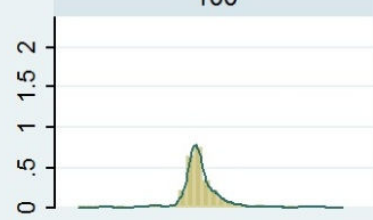

250

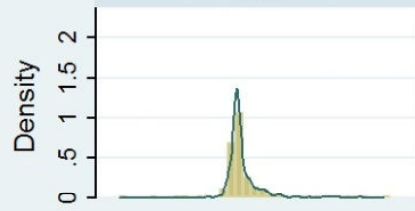

500

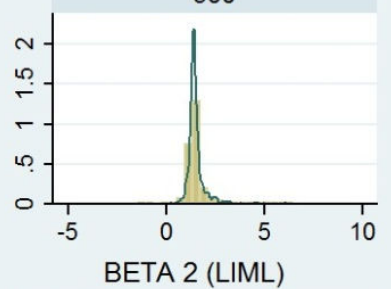

Density

kdensity b2_liml
100

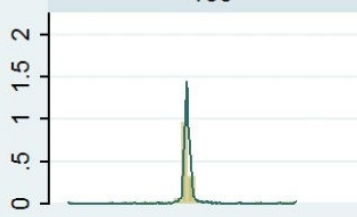

250

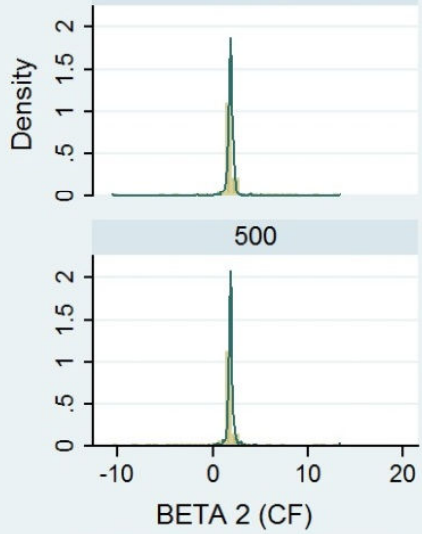

Density

kdensity b2_fc 
FIGURE 12 - Histograms of Example $3\left(\beta_{3}\right)$

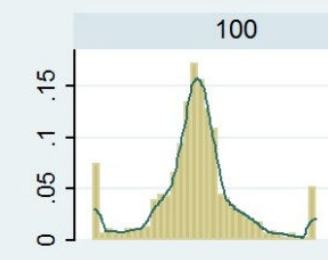

250

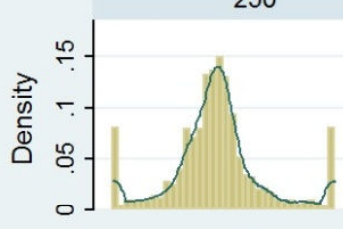

500

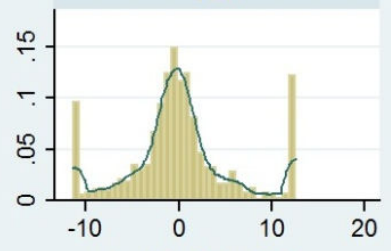

BETA 3 (NL2SLS)

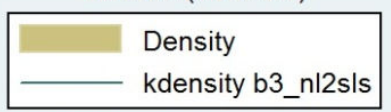

Graphs by Sample Size
100

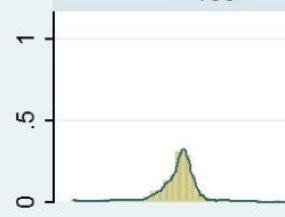

250

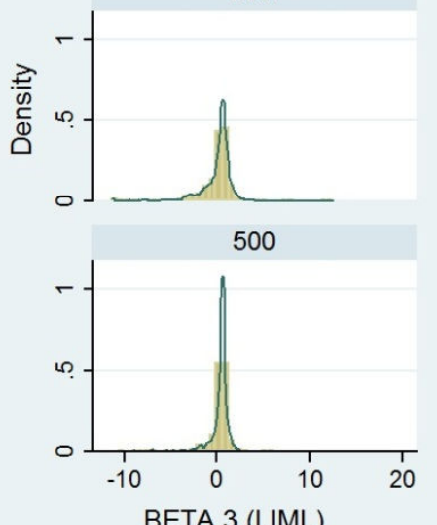

Density

kdensity b3_liml

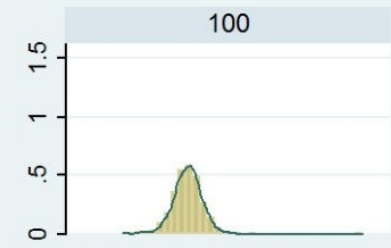

250

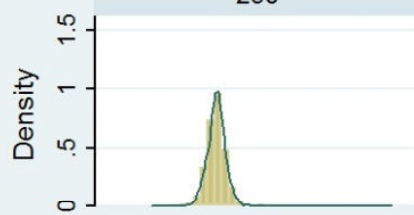

500

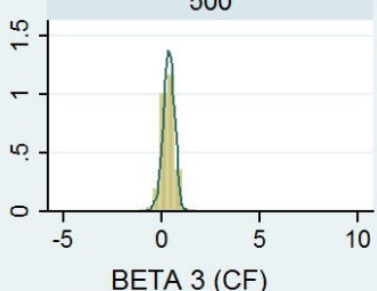

Density kdensity b3_fc 
FIGURE 13 - Histograms of Example $4\left(\beta_{4}\right)$

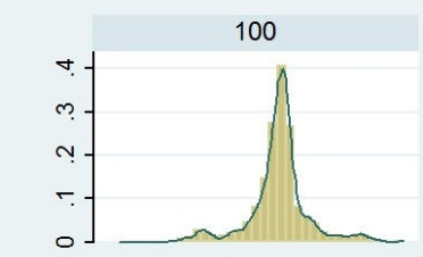

250

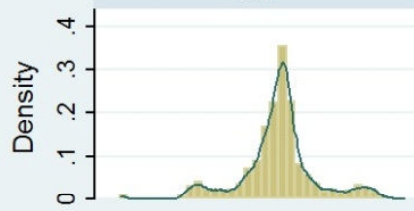

500

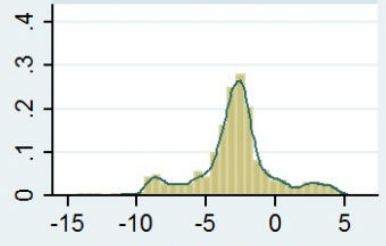

BETA 4 (NL2SLS)

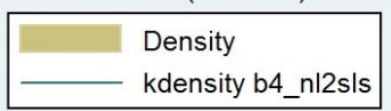

Graphs by Sample Size
100

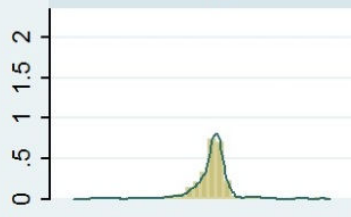

250

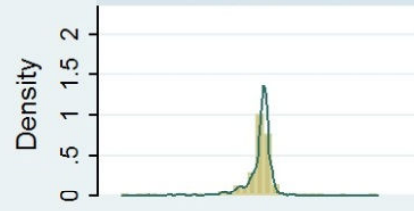

500

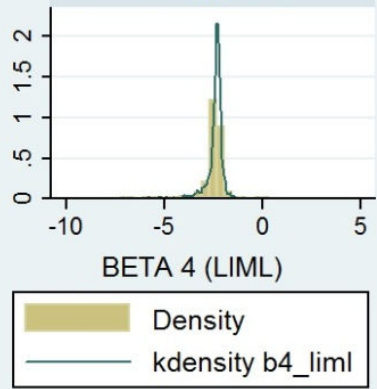

100

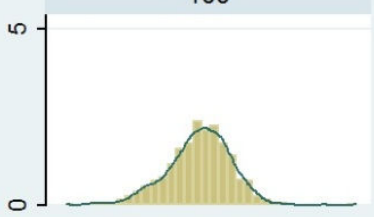

250

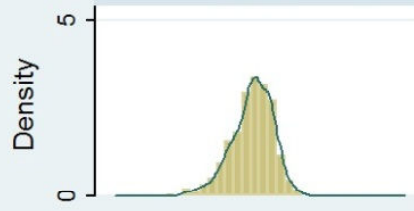

500

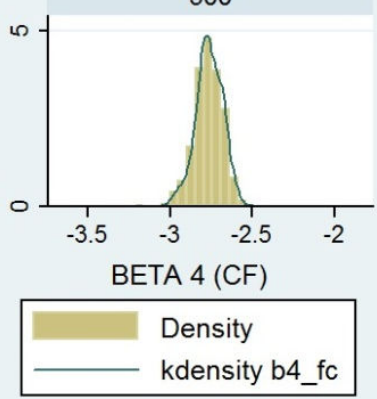


FIGURE 14 - Histograms of Example $3(\gamma)$

100

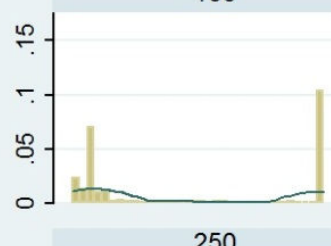

250

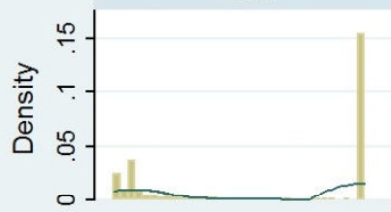

500

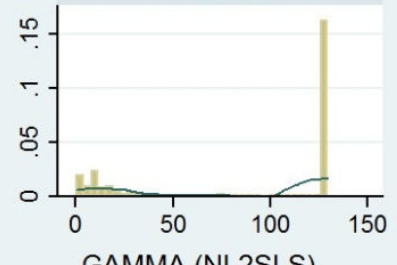

GAMMA (NL2SLS)

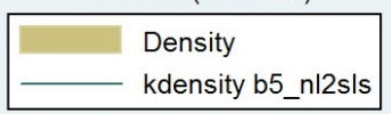

Graphs by Sample Size
100

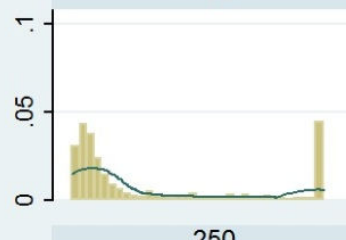

250

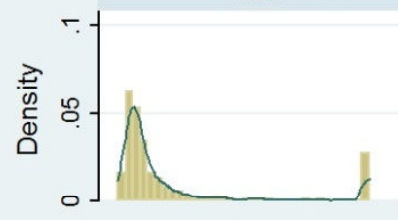

500

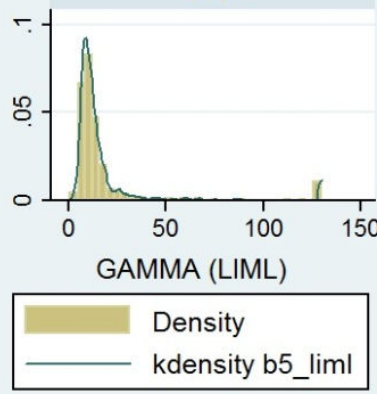

100

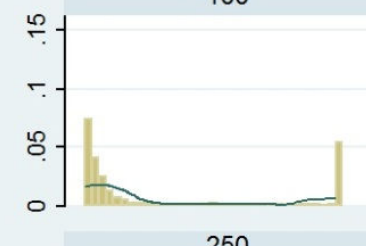

250

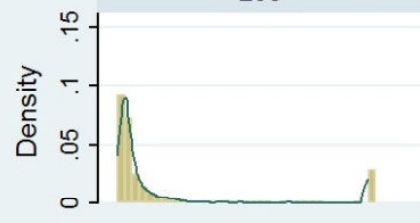

500

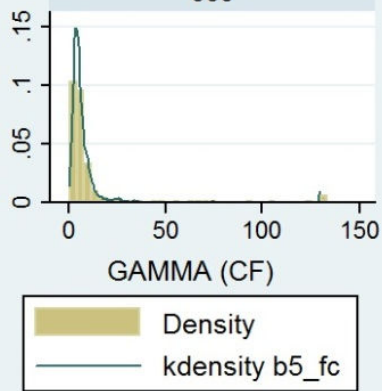


FIGURE 15 - Histograms of Example 3 (c)

100

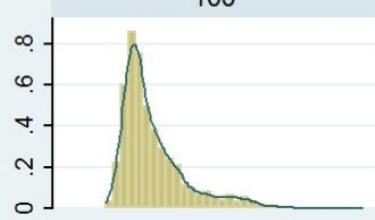

250

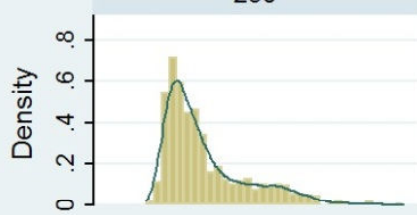

500

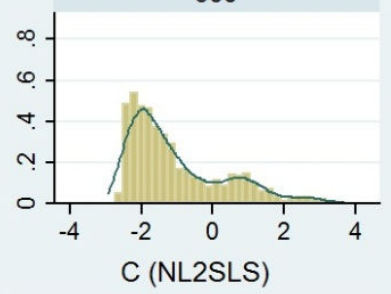

Density

kdensity b6_nl2sls

Graphs by Sample Size
100

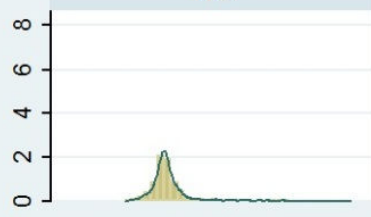

250

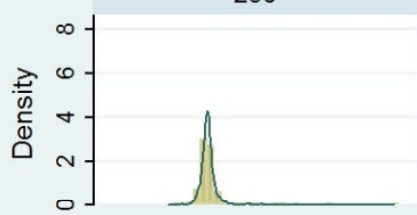

500

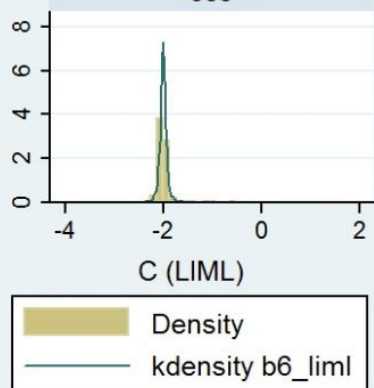

100

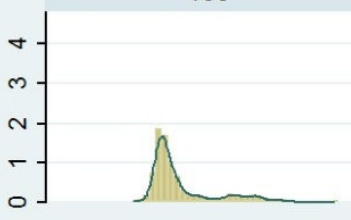

250

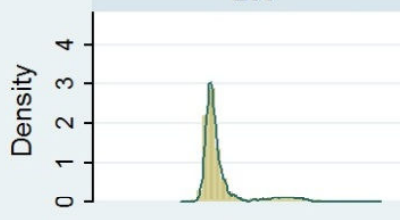

500

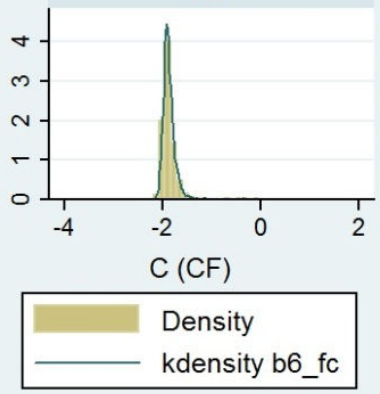

